\title{
Borehole resistivity and induced polarization tomography at the Canadian Shield for Mineral Exploration in north-western Sudbury
}

\author{
Mosaad Ali ${ }^{1,2,}{ }^{*}$, Shulin Sun ${ }^{1}$, Wei Qian ${ }^{1}$, Abdou Dodo Bohari ${ }^{1}$, Dusabemariya Claire ${ }^{1}$, \\ Ajibola Richard Faruwa ${ }^{1}$, and Yan Zhang ${ }^{1}$ \\ ${ }^{1}$ Earth Science and Engineering at Hohai University, 210098, Nanjing, 8 FeChunXiLu, 20, China \\ ${ }^{2}$ Mining and Metallurgy Engineering at Assiut University, 71515, Assiut, University Str., B2, Egypt
}

\begin{abstract}
Mineral exploration in the Canadian shield is a major challenge nowadays. This is because of the thick overburden cover and complex geology. Borehole tomography using resistivity and induced polarization (BHDCIP) method has a big advantage here due to that the data is acquired underneath the cover and data quality, in general, is superior to that acquired at the surface. BHDCIP provides good resistivity and chargeability data, which can identify mineralization easily. In this study, the BHDCIP survey with high-resolution data was carried out to identify mineralization zones in the McCreedy West zone, north-western Sudbury, Ontario, Canada. Two and three-dimensional (2-D and 3-D) inversion results of three boreholes clearly revealed the mineralization zones and that harmonised with previous geological studies in the study area. The BHDCIP method provided insight and developed an informative subsurface map to identify the mineralization zones, thus proving it as a beneficial tool used for mineral exploration in complex geology with a minimal data survey and an irregular geometrical distribution.
\end{abstract}

\section{Introduction}

Geoelectrical methods (direct current (DC) resistivity and IP) have demonstrated to be a useful and effective tool in the exploration of mineral resources (metallic and non-metallic) $[1,2]$. Especially, the IP method is widely used for mineral exploration because it is the only geophysical technique that has the ability to discriminate conductive or semiconductive minerals disseminated in high electrical resistivity background (host rock) [37].

Borehole resistivity and chargeability tomography (BHDCIP) can give valuable help to mineral exploration applications, especially with ore-deposits that have thick overburden cover and complex geology. In-hole datasets can supply information on the DCIP signatures of key lithologies and mineralization, hence enabling improved an understanding of which geophysical signature reflects geologic features of interest [8-12]. Off-hole datasets provide information on the spatial extent and the orientation of in-hole features, in

*Corresponding author: mossad_ali2000@aun.edu.eg 
addition to identifying off-hole targets. Spatial resolution is effectively carried out through cross-hole tomography (CHT). CHT is achieved through quadrupole measurements using several combinations of current $(\mathrm{AB})$ and potential $(\mathrm{MN})$ electrodes at different places to gain a very high-resolution image [13].

Multi-electrode datasets acquisition systems and adequate algorithms of 2D/3D inversions have been significantly developed and increasingly applied in DCIP surveys over the past two decades in the geoengineering and environmental fields [14-17]. In contrast, the applications of 2D and 3D inversions for mineral exploration have been limited because of challenges posed by non-planar geometries of the BHs and inevitably large mesh sizes which very complicate the inversion treatment. The adaptability of an Occam-type of the inversion is tested on high-resolution CHT datasets to evaluate its ability to render geologically illustrative information in the mining and exploration fields [18].

In this work, the BHDCIP data acquired by DCIP technique is applied to find out the distribution of mineralized zones and underground formation description of the massive sulphide deposits based on resistivity and chargeability values. We collected numerous single BH VP (Vertical Profiling) and CHT (BH-to-BH tomography) datasets across numerous different massive sulphide deposits. Here we describe results from datasets collected in the McCreedy West zone, northwest of Sudbury, Ontario, Canada. The BHs were water-filled and $\mathrm{BH}$ to $\mathrm{BH}$ separation varied from $40 \mathrm{~m}$ to $130 \mathrm{~m}$. The data acquisition system (RESECS II) was developed by GeoServer at Germany for geophysical applications. What is novel about the BHDCIP system is its BH cable and electrode design, which provide a seamless combination of $\mathrm{BH}$ and surface measurements. The BHIP datasets of the surveying have been described and analysed as the VP pseudo-sections for every single BH separately using Schlumberger standard configuration to identify probable variants of apparent resistivity and chargeability features. Moreover, 2-D and 3-D inversions of CHT were carried out based on the finite element method and 3-D view of the inverted datasets to assist in the interpretation.

We have demonstrated that the high-resolution DCIP system is able to collect meaningful data to aid mineral exploration, despite less than ideal $\mathrm{BH}$ geometries. Inversion results have confirmed to provide the accurate spatial agreement of the information collected by both single VP and CHT. This makes the BHDCIP tomography a valuable exploration tool for mineral exploration. The inverted models revealed a good agreement with the existing geological features in the study area. The study recommends that if pre-existing information regarding the geological environment is available, then BHDCIP data (resistivity and changeability) can be a helpful and fascinating mixture for mineral exploration.

\section{Geological characteristics and Mineralization}

The Property is located $\left(46^{\circ} 50^{\prime} 35.46^{\prime \prime} \mathrm{N}, 81^{\circ} 10^{\prime} 44.09^{\prime \prime} \mathrm{W}\right)$ around $35 \mathrm{~km}$ north-west of Sudbury, Ontario in Figure 1. Sudbury is considered as one of two major producers of the nickel-copper $(\mathrm{Ni}-\mathrm{Cu})$ and for ordering as the world's largest $\mathrm{Ni}-\mathrm{Cu}$-deposit [19-21]. Sudbury has one of the biggest mining camps, and some of these mines have been operating almost continuously for more than 100 years [22]. $\mathrm{Ni}-\mathrm{Cu}$ sulphide ores are typically formed by balancing the immiscible magmatic sulphide and silicate magma [23].The full description of the geological setting at Sudbury illustrated in [24-28].

SIC "Sudbury Igneous Complex" is a $1.85 \mathrm{Ga}$ (billion years ago) an elliptical rock body (basin) located on the border between the Proterozoic Huronian and the Superior Craton Belt to the south in Figure 1 [29-32]. The SIC is mainly subdivided into the upper series of granophyre, the central series of the gabbroic rocks, and the lower series of the noritic rocks in Figure 2a [33]. It is generally accepted that the SIC is the outcome of a meteorite impact 
event [27], and the manner that led to $\mathrm{Ni}-\mathrm{Cu}$ ores deposit has now been harmonized with this genetic model $[34,35]$. Ni-Cu sulphide mineralization is found proximal to the centre of the SIC in three major environments Figure 2b-f [32].

The Sublayer, an irregular unit of inclusion-rich metamorphic-textured granite and igneous-textured norite found in depressions at the centre of the SIC [36]. The main Cu-Ni ore deposits at the Sudbury Basin are located in the sublayer, the sulphide deposits content in the sublayer changes from massive ore to finely disseminated ore grade [37]. The mineralization in the noritic Sublayer forms the structure to a leucocratic footwall breccias usually include lenses of disseminated and massive sulphides Figure 2b-c [38, 39].

Offset Dykes, mineralization associated with spreading dikes of quartz diorite and connected with it in the breccia belt, which flanks the southern portion of the SIC. So, these dikes are called "Offset Dikes" (OD). Within the OD and belt of Frood Stobie Breccia Figure 2d-f [19, 24].

Footwall mineralization, the SIC footwall is usually strongly brecciated with the growth of the pseudotachylite vein system; this vein system is crosscut by Ni-Cu-rich mineralization of the vein style that is locally led to as "footwall mineralization" Figure 2c. This mineralization appears sharp-walled veins which crosscut the Archean gneisses in a distance of several hundred meters away from the initial centre of the SIC and as a continuous zone in a distance of up to $1 \mathrm{~km}$; these veins locally are usually associated with pieces of trace disseminated sulphides that offer elevated precious ore abundance levels [19].

Also, there are several numbers of ore-deposits at Sudbury which similar characteristics in one of these groups [39].

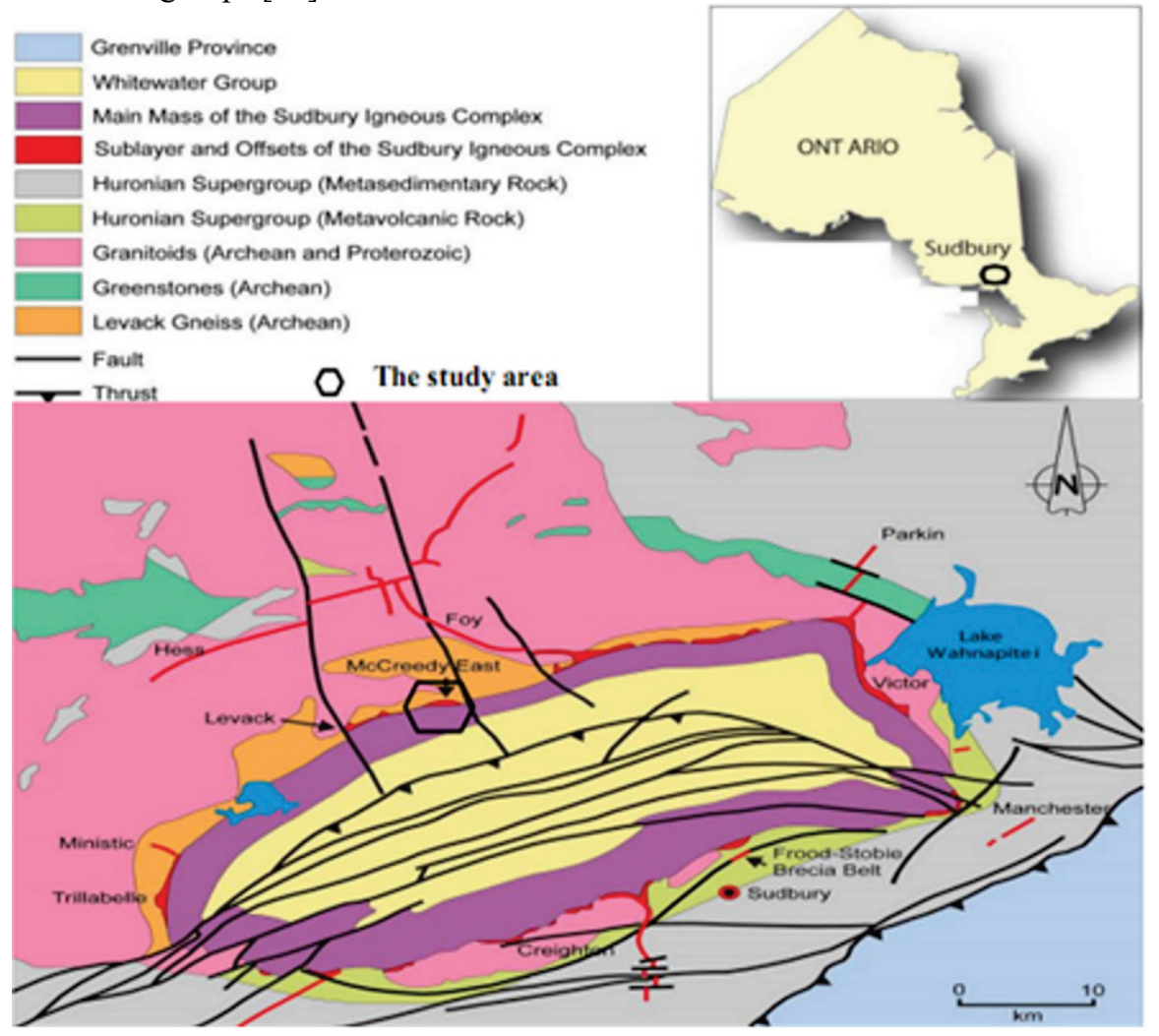

Fig. 1. Geological map of the SIC, illustrating the location of the Sublayer, Offset dikes and the study area at the outer margin of the Main Mass [28]. 


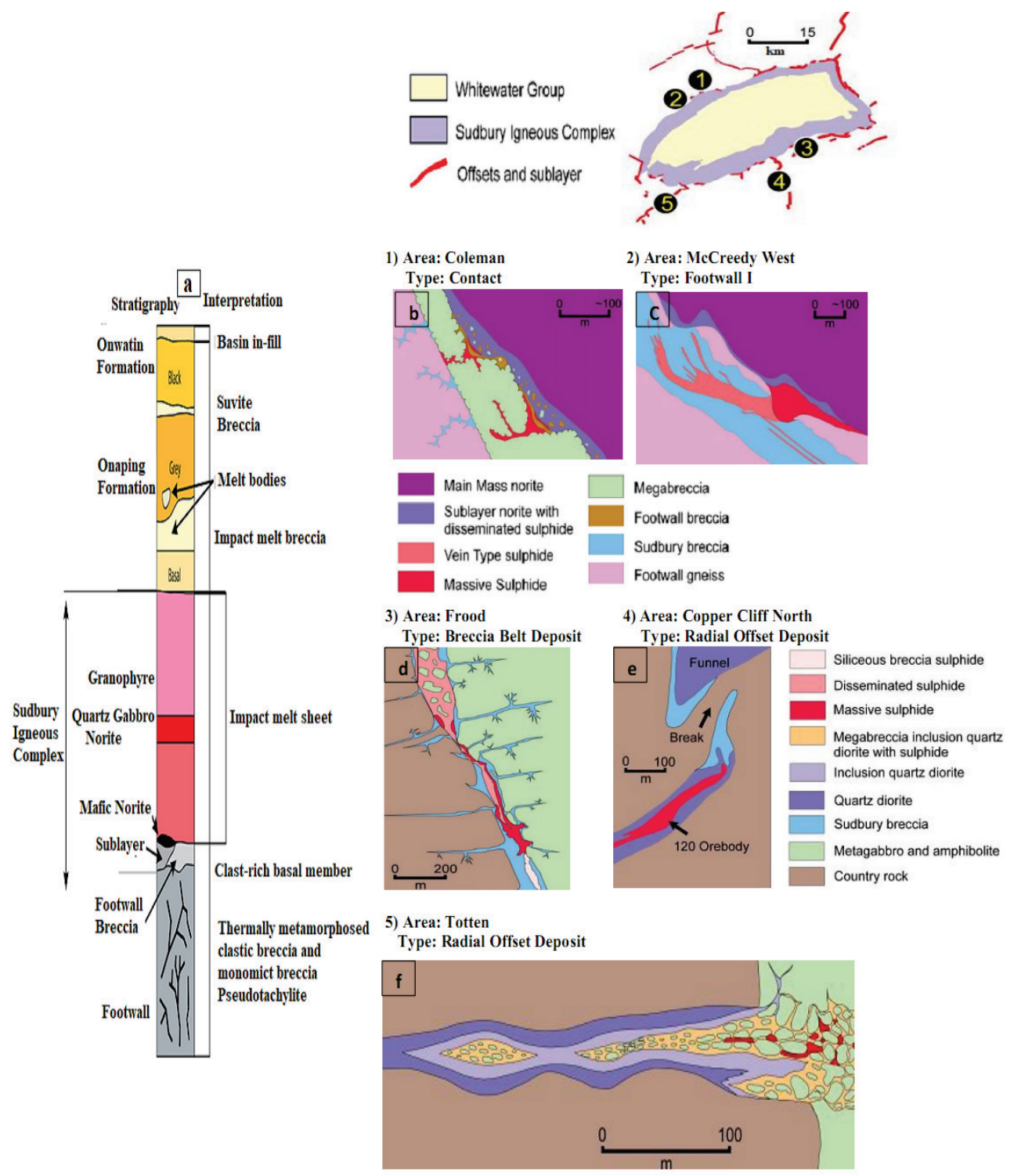

Fig. 2. a) Geological relationships and stratigraphic at the SIC and their interpretation according to the meteorite impact hypothesis based on [30], b-f) the geology and mineralization of the main types of Ni-Cu sulphide ore deposits in Sudbury [22].

\section{Materials and Methods}

\subsection{IP theory and processing}

When the voltage is applied to the ground, the electricity flows mostly into the electrically filled capillaries inside the rock [40]. There are two mechanisms which describe the IP effects, one of them is electrode polarization, due to the presence in pores of some metal particles that carry current through electrons and the second mechanism is membrane polarization, due to existent the clay particles in a formation medium [41, 42]. Most of IP 
measurements for mineral exploration are conducted in the time-domain (TD) and include the combined IP impacts of membrane and electrode polarization [43-45]. The IP surveying consists of measuring the potential decay after switching-off the transmitted current to get the apparent chargeability $\left(M_{a}\right)$, which is a measure of the strength of the IP effect. Therefore, IP measurement of chargeability represents the integrated area under a chosen portion of the decay potential curve $\left(V_{t}\right)$ as shown in Figure 3 and Equation 1 [46]. The potential decay is always measured for positive and negative polarities to cancel DC effects due to self-potential and natural telluric currents.
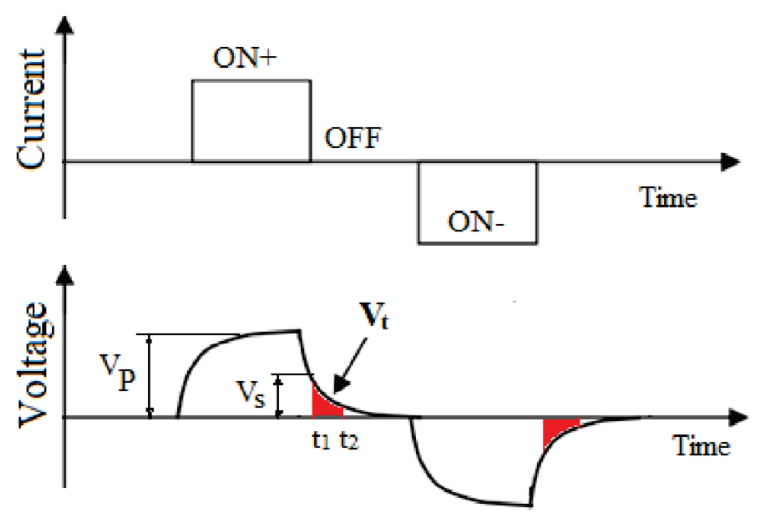

Fig. 3. Time Domain IP Waveform.

$$
M_{a}=\frac{1}{V_{p}} \int_{t_{1}}^{t_{2}} V_{s}(t) d t
$$

where $V_{p}$ is the primary voltage, $V_{s}$ represents secondary voltage, and $V_{t}$ is the voltage decay with a time interval between $t_{1}$ and $t_{2}$.

The measured voltage with injected current is converted into apparent resistivity $\left(\rho_{a}\right)$ by a geometric factor which considers the air-earth interface, as in Equation 2 [47].

$$
\rho_{a}=k \frac{\Delta V}{I}
$$

where $k$ is a geometrical factor,

$$
k=\frac{4 \pi}{\frac{1}{r_{M A}}+\frac{1}{\dot{r}_{M A}}-\frac{1}{r_{M B}}-\frac{1}{\dot{r}_{M B}}-\frac{1}{r_{N A}}-\frac{1}{\dot{r}_{N A}}+\frac{1}{r_{N B}}+\frac{1}{\dot{r}_{N B}}},
$$

$r, \dot{r}$ are the distances of the real and mirror effect of the ground surface at potential points $(M, N)$ respectively; $\Delta V$ is the measured difference potential at points $M$ and $N ; l$ is the applied electric current.

\subsection{Survey configurations}

To delineate and map mineralization zones, the exploration has been conducted by EarthProbe RESECS devices using high resolution and accurate dataset. The boreholes survey was carried out for every single borehole separately and cross-borehole tomography between every two boreholes, to identify probable variants of resistivity and chargeability features. 
Figure 4 shows the data acquisition system (REAleCof the resistivity and chargeability. This system can an arbitrary selection of current and potential electrodes by relay switches. Rapid data acquisition and advanced digital signal processing provide for efficient use of conventional and novel arrays and the elimination of natural and artificial noise. This design permits the deployment of numerous hundred electrodes at once and data acquisition is taken out automatically [48].

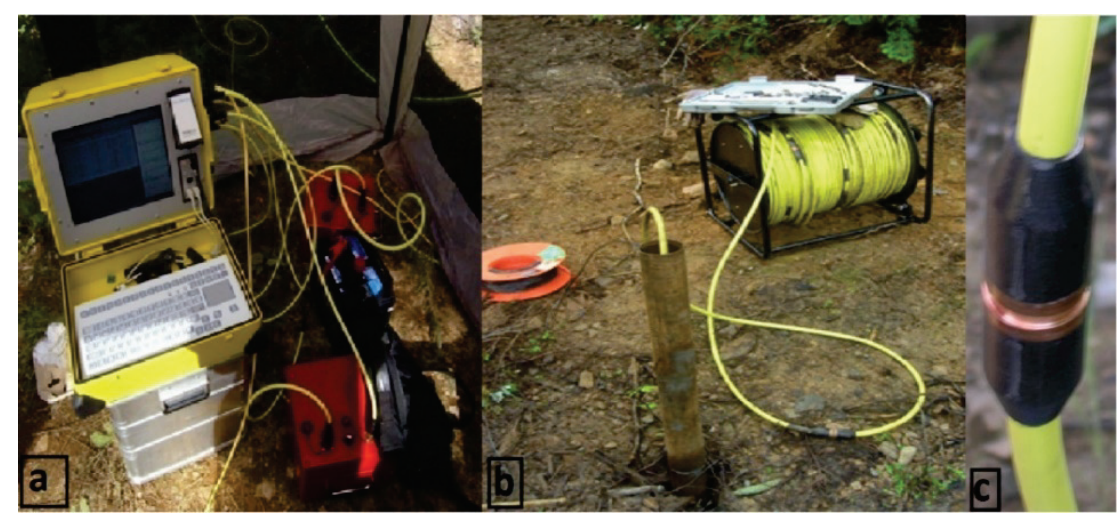

Fig. 4. The data acquisition system components: a) RESECSI device, b) BH electrodes cable and c) Copper-ring electrode.

We use BH cables with 24 electrodes spaced at every $4 \mathrm{~m}$. VP data in a single BH are collected with the current and potential electrode setup the same as for a surface Schlumberger survey Figure 5.

VPs provide information about in-hole characteristics and can detect off-hole characteristics up to $25 \mathrm{~m}$ from the $\mathrm{BH}$. The resistivity and chargeability datasets collected at the $\mathrm{BH}$ can also be used to render realistic bulk rock features of the host-rocks and mineralized zones for enhanced characterization [13].

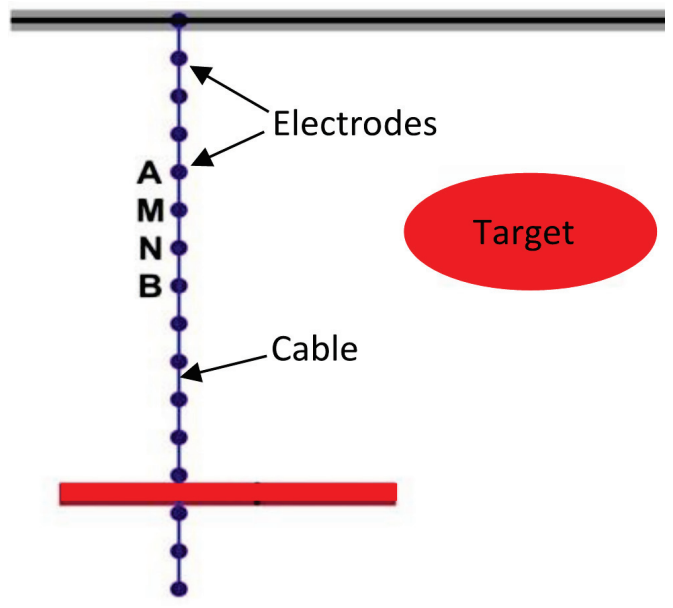

Fig. 5. Electrode configuration for vertical profile surveys.

The tomography data are collected with electrodes straddle across BHs as shown in Figure 6 . This configuration ensures reliable datasets quality and gives detailed information regarding resistivity distribution between the $\mathrm{BHs}$ and help in determining the direction and connectivity of in-hole characteristics between $\mathrm{BHs}[8,9,49]$. This configuration was suggested and successfully described by [50]. 


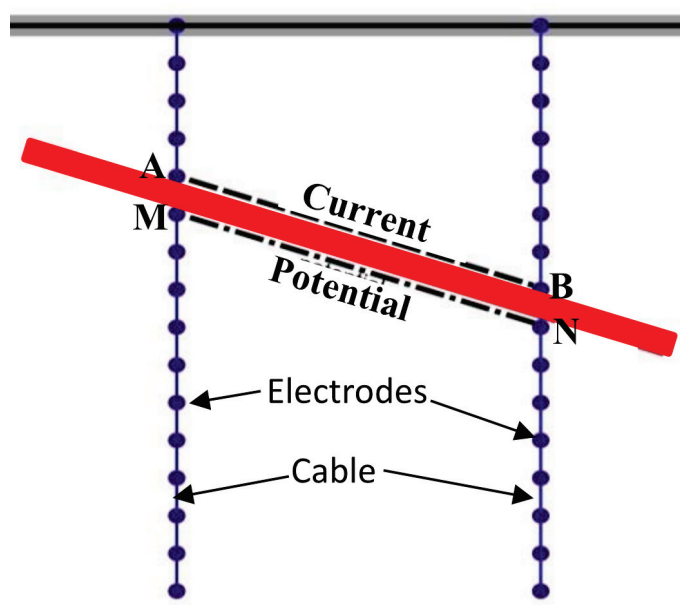

Fig. 6. Tomography measurements with electrodes straddle across two BHs.

\subsection{Repeatability Study}

In order to carry out meaningful studies, the method employed has to be fully repeatable. An experiment was performed to evaluate the repeatability of DCIP surveys. A castle waveform of the current is injected into the formation with 4 periods: positive on and off followed by negative on and off. Two main configurations are considered: $\mathrm{BH}$-surface and $\mathrm{BH}-\mathrm{BH}$.

The BH-surface study involves both $\mathrm{BH}$ and surface electrodes for current and potential. Figure 7 shows five repeated recordings, with current injection on the left and voltage response on the right. It is observed that the source is very robust. However, potential readings exhibit significant fluctuations. In contrast, the $\mathrm{BH}-\mathrm{BH}$ (cross-hole) study is highly repeatable in both current and voltage signals Figure 8, which makes it suitable for exploration and monitoring purposes.
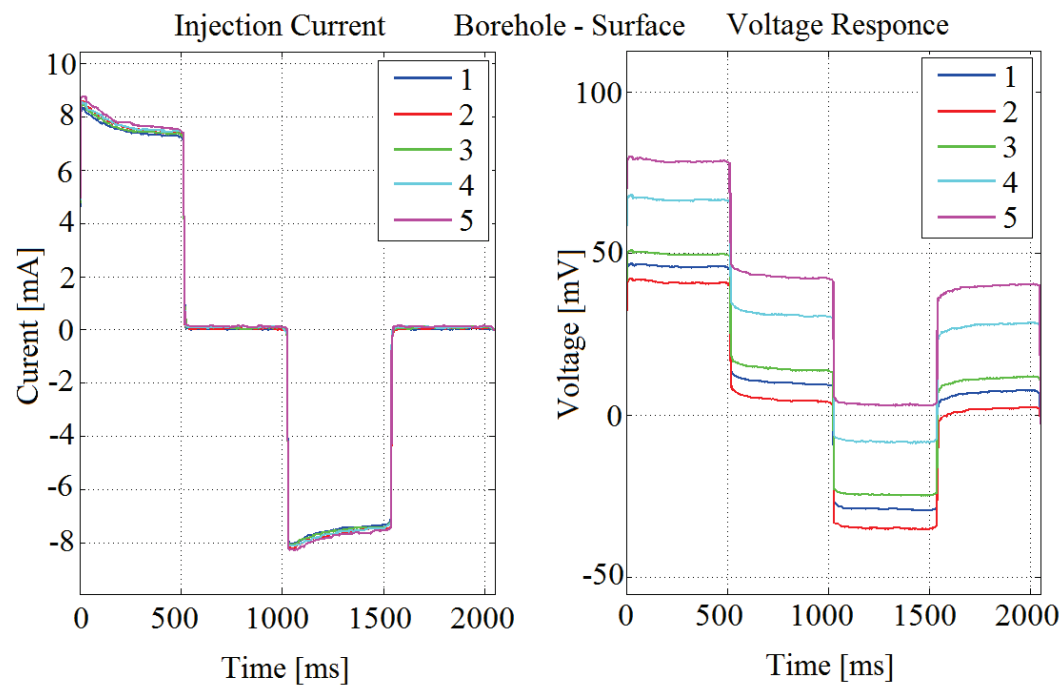

Fig. 7. Example of five repeated measurements from BH-surface study. 

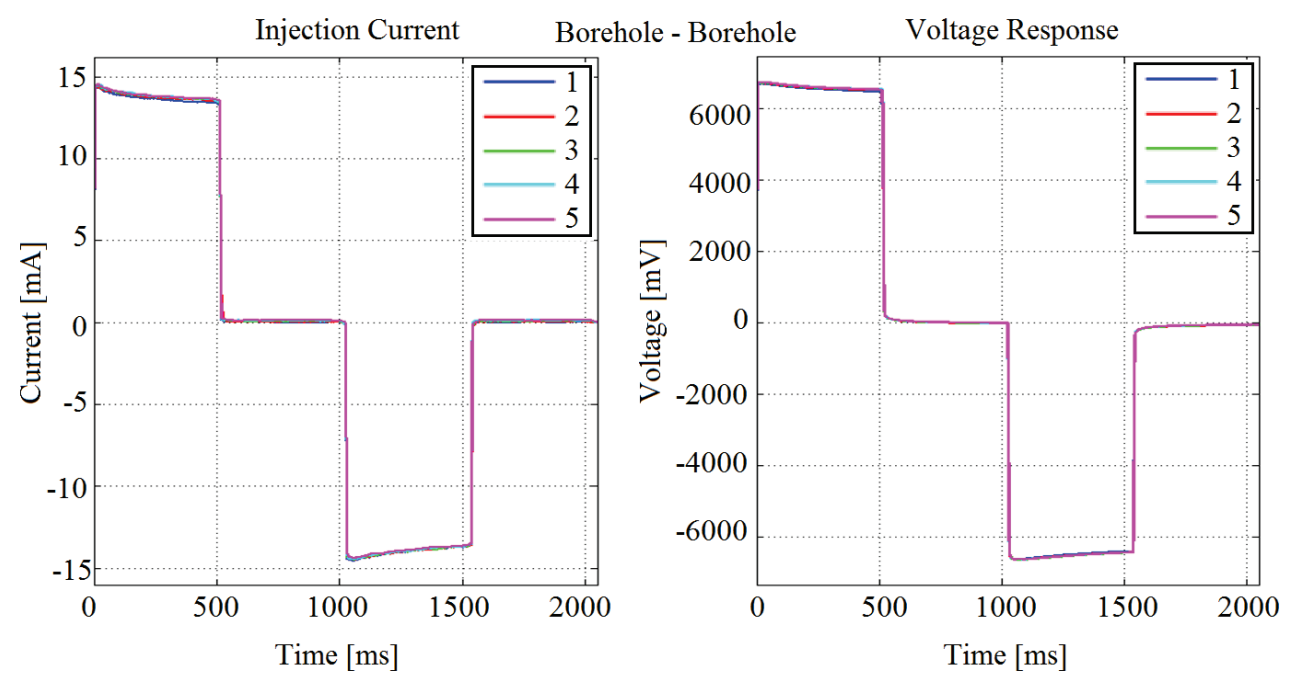

Fig. 8. Example of five repeated measurements from $\mathrm{BH}-\mathrm{BH}$ study.

\subsection{Quality Assurance (QA) and Quality Control (QC)}

To ensure reliability and maintain the required quality level in the measured data, the survey was conducted in accordance with QA\&QC. Several QA\&QC standard criteria have implemented throughout the survey to evaluate the quality of the measured datasets. Acceptable thresholds have been confirmed by the operator in accordance with industryaccepted practices and site-specific conditions. Table 1 shows the QA\&QC criteria applied to this survey.

Table 1. Criteria for verification of QA\&QC data during the survey.

\begin{tabular}{|c|c|c|}
\hline Survey Item & QA\&QC Survey & $\begin{array}{c}\text { Acceptable } \\
\text { Threshold }\end{array}$ \\
\hline Waveform & $\begin{array}{l}\text { The current and voltage waveforms must be a } \\
\text { "castle shape" also the current and voltage time- } \\
\text { series correlation of must be above a specified } \\
\text { threshold }\end{array}$ & 0.9 \\
\hline Injection current & $\begin{array}{l}\text { The injected current has to within a specified } \\
\text { range }\end{array}$ & Above $1 \mathrm{~mA}$ \\
\hline $\begin{array}{l}\text { Measured } \\
\text { voltage }\end{array}$ & $\begin{array}{c}\text { The measured voltage has to within a specified } \\
\text { range }\end{array}$ & $\begin{array}{c}5-10,000 \\
\mathrm{mV}\end{array}$ \\
\hline Stacked voltages & $\begin{array}{c}\text { The standard deviation of processed (stacked) } \\
\text { voltage dataset must be below a determined } \\
\text { threshold }\end{array}$ & $5 \%$ \\
\hline Self-potential & $\begin{array}{l}\text { The self-potential system must be below a } \\
\text { determined threshold }\end{array}$ & $100 \mathrm{mV}$ \\
\hline
\end{tabular}

\subsection{Survey layout}

There are three BHs surveyed in this demonstration study. The collar locations of these three bores are shown in Figure 9. Two holes are almost aligned in the east-west direction, 
while one hole is about $200 \mathrm{~m}$ north. This $\mathrm{BH}$ configuration is not ideal for tomography surveys.

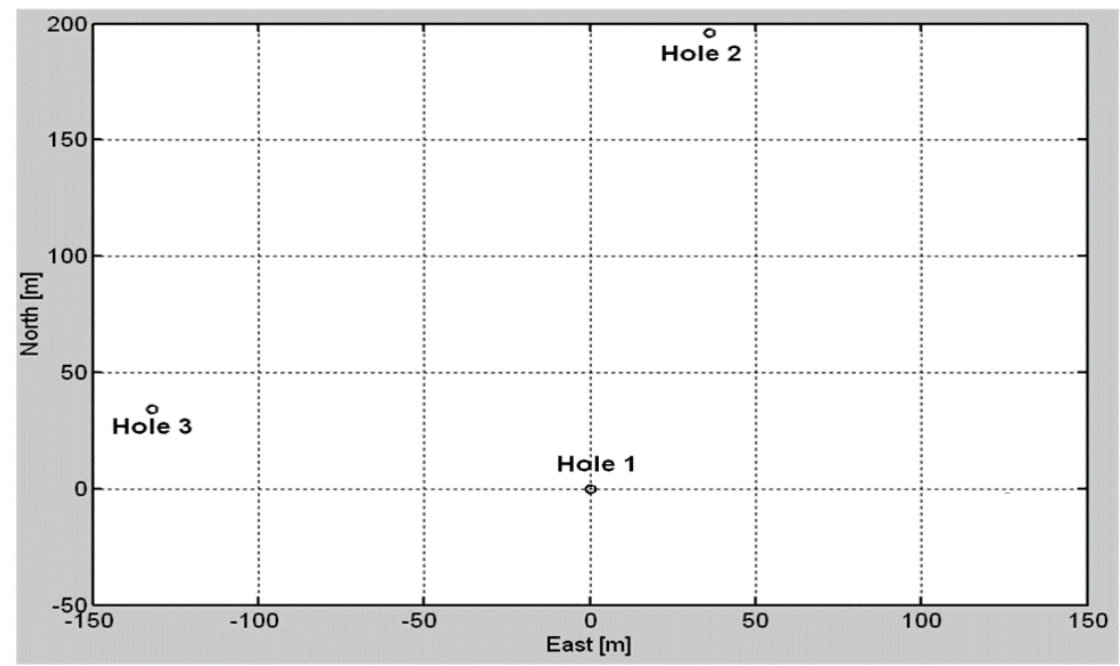

Fig. 9. Three BHs were surveyed in this demonstration project.

\section{Results and Discussion}

\subsection{Vertical profile data}

The vertical profile data collected in hole 1 Figure 10 shows that there is a massively conductive and chargeable zone being intersected by this $\mathrm{BH}$ between the depth of 10 to $25 \mathrm{~m}$ along the $\mathrm{BH}$. The chargeable zone, however, appears a little bit deeper. This zone extends beyond $10 \mathrm{~m}$ away from the $\mathrm{BH}$. Because our $\mathrm{BH}$ cable can only reach the depth of $60 \mathrm{~m}$, we cannot estimate this zone's extension beyond $10 \mathrm{~m}$ from a single $\mathrm{BH}$ measurement.
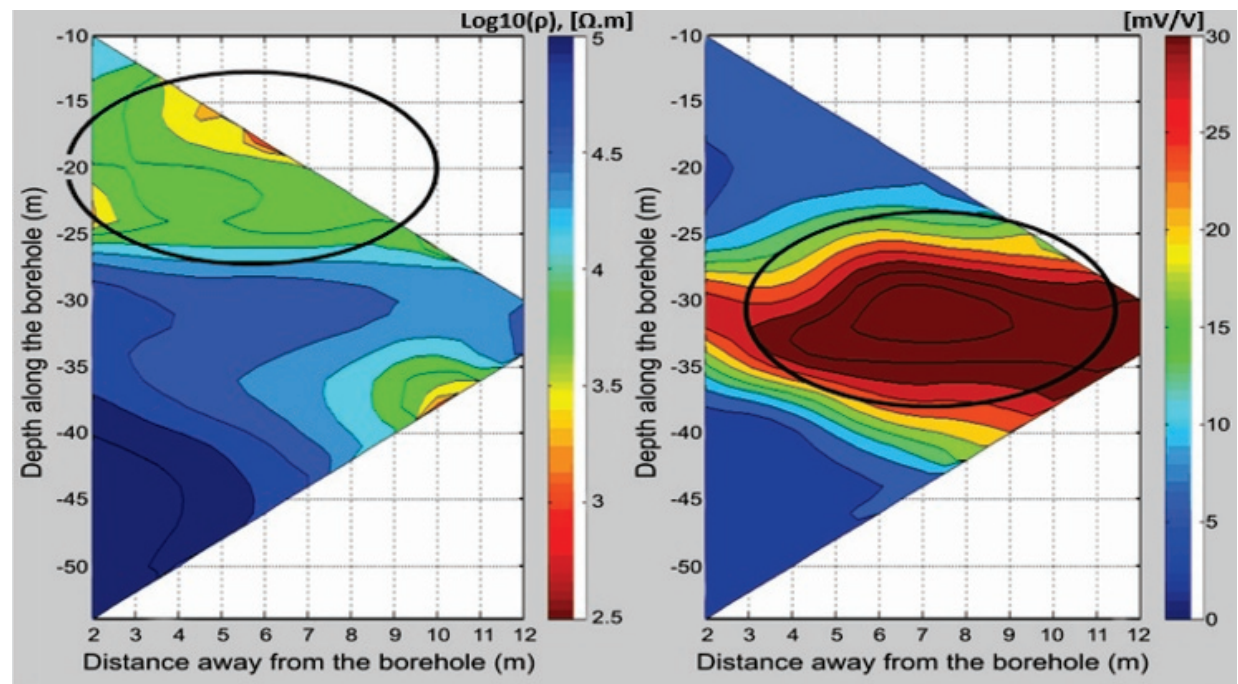

Fig. 10. Vertical profile apparent resistivity and chargeability in hole 1. 
The vertical profile data collected in hole 2 Figure 11 shows that there is not massively conductive and chargeable zone being intersected by this $\mathrm{BH}$. However, there is a conductive and strongly chargeable zone about $10 \mathrm{~m}$ away from this $\mathrm{BH}$. This zone seems to extend shallower as it is going away from this $\mathrm{BH}$.

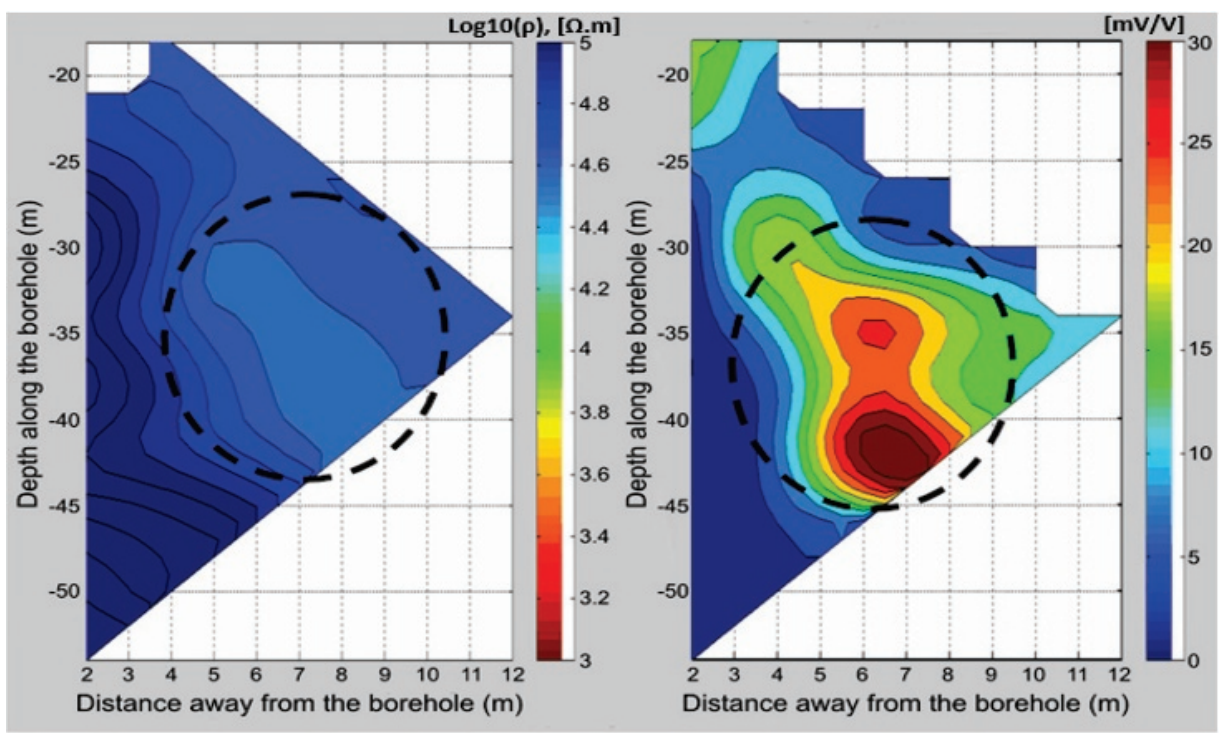

Fig. 11. Vertical profile apparent resistivity and chargeability in hole 2.

The vertical profile data collected in hole 3 Figure 12 shows that there is not massively conductive and chargeable zone being intersected by this $\mathrm{BH}$. However, there is a moderately conductive and chargeable zone about $20 \mathrm{~m}$ away from this $\mathrm{BH}$. This zone seems to extend shallower as it is going away from this $\mathrm{BH}$.

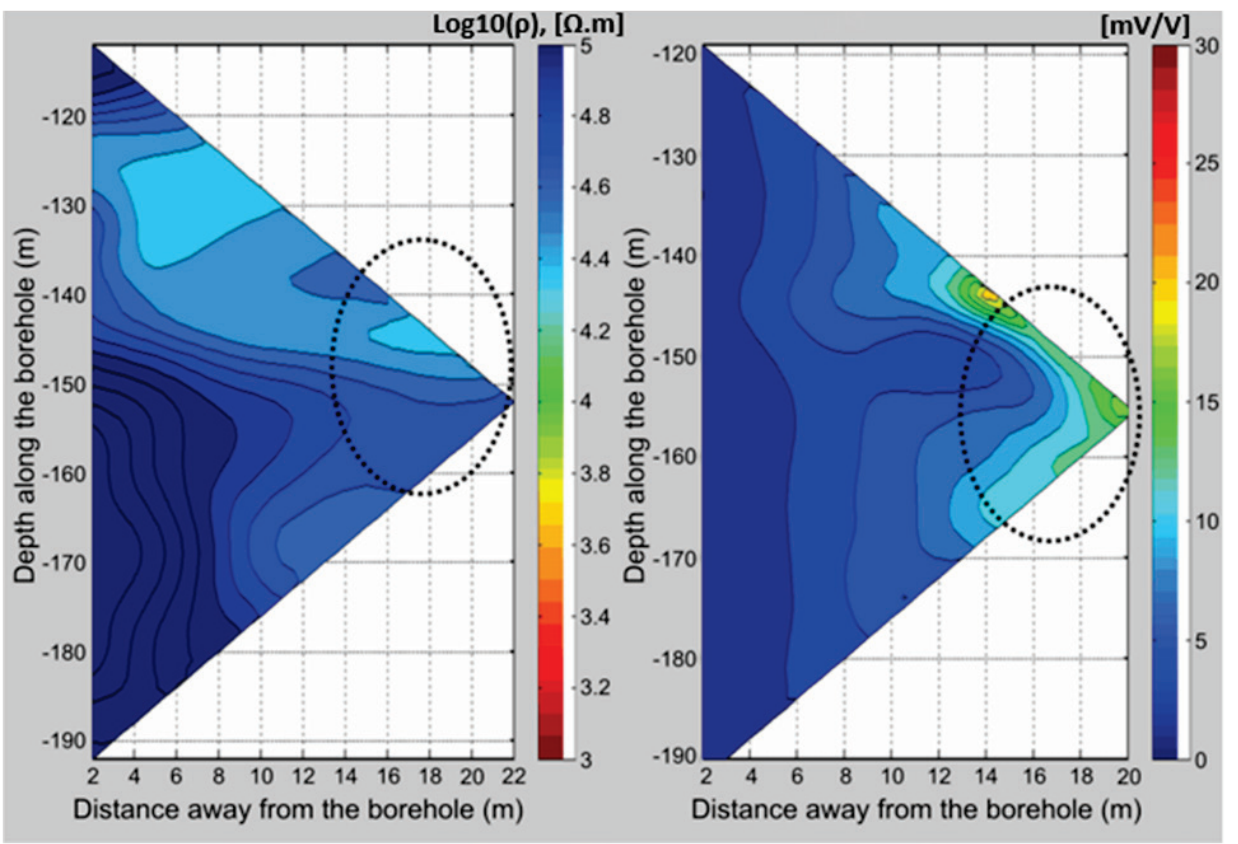

Fig. 12. Vertical profile apparent resistivity and chargeability in hole 3. 
All these data behaviours can be explained by the fact that the mineralization intercepted by hole 1 at the shallow depth does not reach holes 2 and 3. This mineralization stops about $10 \mathrm{~m}$ away from holes 2 and 3 .

\subsection{Tomography data and inversion results}

The tomography data confirms that the mineralization intercepted by hole 1 does not reach to holes 2 and 3 as shown in Figure 13, where the low resistivity zone at a shallow part of hole projects almost to hole 3 at the depth of $115-145 \mathrm{~m}$. This same feature projects to hole 2 at a wide depth range, indicating that it stops at a distance towards hole 2 .

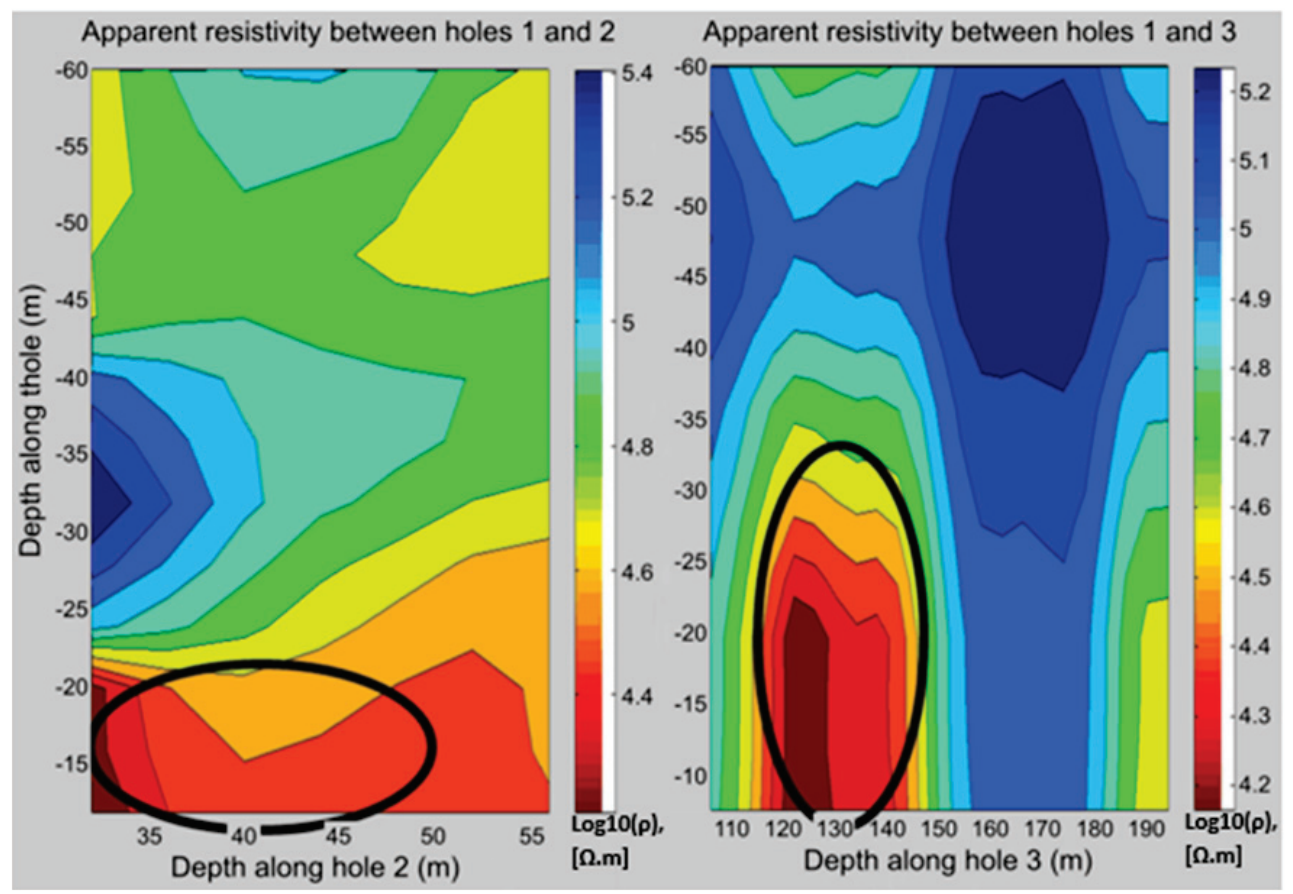

Fig. 13. 2-D inversion of apparent resistivity tomography data between holes 1-2 and 1-3.

Preliminary bulk resistivity and chargeability characterization of the lithologies encountered in hole No 1 was undertaken using the in-hole apparent resistivity and chargeability information collected during the vertical profiling of the $\mathrm{BHs}$ and $\mathrm{BH}$ assay information. Based on that, massive sulphide mineralization zone in SIC existed in sublayer footwall as shown in Figure $2 \mathrm{C}$. The mineralized zone exhibited average resistivities $(<=80 \Omega . \mathrm{m})$ and chargeability $(>=20 \mathrm{mV} / \mathrm{V})$ for an average assay is $(1.60 \% \mathrm{Ni}$ and $1.30 \% \mathrm{Cu}$ ) and an average density $2.7 \mathrm{~g} / \mathrm{cm}^{3}$ [36]. The results of 3-D inversion were visualized in a 3-D model using ParaView freeware, as shown in Figure 14 where it corresponds to the geological characteristics of the area and it confirms again that the mineralization zone intersects with hole 1, almost reaches holes 2 and away from hole 3. The total volume of the mineralization zone is $1120.589 \mathrm{~m}^{3}$ calculated by the ParaView. From the volume and density of the sulphide ore, the predicted geological reserve of the sulphide ore is 3025.590 tons in this area. 


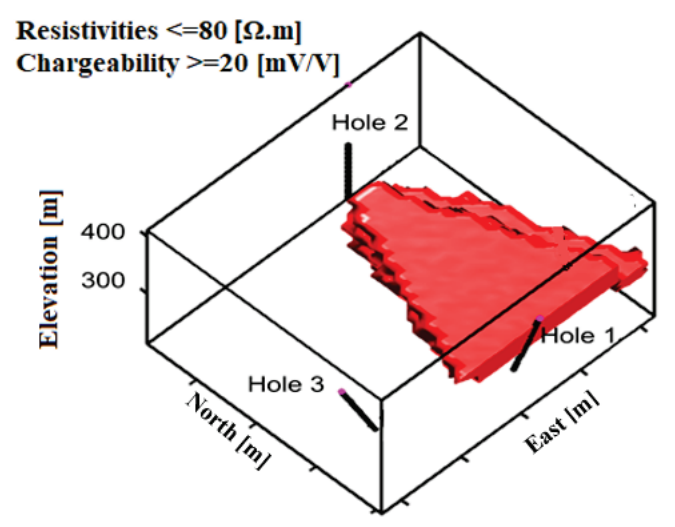

Fig. 14. 3D inversion model of the BHDCIP data.

\section{Conclusions}

The mineralization zone is clearly identified by BHDCIP data of the single-borehole and cross-borehole survey. We have demonstrated that the high-resolution DCIP system is able to collect meaningful data to aid mineral exploration, despite less than ideal $\mathrm{BH}$ geometries. The 2-D and 3-D inversion results have confirmed to provide the accurate spatial agreement of the information collected by both single VP and CHT. The predicted geological reserve of the (Ni-Cu) sulphide ore in the study area was calculated. The BHDCIP method provided insight and developed an informative subsurface map to identify the mineralization zones, thus proving it as a beneficial tool used for mineral exploration in complex geology with a minimal data survey and an irregular geometrical distribution.

\section{References}

1. J. M. Reynolds, An introduction to applied and environmental geophysics (John Wiley $\&$ Sons, 2011)

2. G. Zhang, Q.-T. Lü, P.-R. Lin, G.-B. Zhang, Electrode array and data density effects in 3D induced polarization tomography and applications for mineral exploration. Arab. J. Geosci. 12, 221 (2019)

3. W. H. Pelton, S. H. Ward, P. G. Hallof, W. R. Sill, P. H. Nelson, Mineral discrimination and removal of inductive coupling with multifrequency IP. Geophysics. 43, 588-609 (1978)

4. P. H. Nelson, G. D. Van Voorhis, Estimation of sulfide content from induced polarization data. Geophysics. 48, 62-75 (1983)

5. G. Gurin, K. Titov, Y. Ilyin, Induced Polarization of Rocks Containing Metallic Particles: Evidence of Passivation Effect. Geophys. Res. Lett. 46, 670-677 (2019)

6. C. L. Bérubé, G. R. Olivo, M. Chouteau, S. Perrouty, Mineralogical and textural controls on spectral induced polarization signatures of the Canadian Malartic gold deposit: Applications to mineral exploration. Geophysics. 84, B135-B151 (2019)

7. L. Lévy, P. K. Maurya, S. Byrdina, J. Vandemeulebrouck, F. Sigmundsson, K. Árnason, T. Ricci, D. Deldicque, M. Roger, B. Gibert, others, Electrical resistivity tomography and time-domain induced polarization field investigations of geothermal areas at Krafla, Iceland: comparison to borehole and laboratory frequency-domain electrical observations. Geophys. J. Int. 218, 1469-1489 (2019)

8. J. J. Daniels, Three-dimensional resistivity and induced-polarization modeling using 
buried electrodes. Geophysics. 42, 1006-1019 (1977)

9. H. Shima, 2-D and 3-D resistivity image reconstruction using crosshole data. Geophysics. 57, 1270-1281 (1992)

10. W. Daily, E. Owen, Cross-borehole resistivity tomography. Geophysics. 56, 1228-1235 (1991)

11. C. A. Moreira, R. A. S. Paes, L. M. Ilha, J. da Cruz Bittencourt, Reassessment of Copper Mineral Occurrence Through Electrical Tomography and Pseudo 3D Modeling in Camaquã Sedimentary Basin, Southern Brazil. Pure Appl. Geophys. 176, 737-750 (2019)

12. Ali, Mosaad, Sun, Shulin, Qian, Wei, Bohari, Abdou Dodo, Claire, Dusabemariya, Zhang, Yan, Application of Resistivity Method for Mining Tailings Site Selection in Karst Regions. E3S Web Conf. 144, 1002 (2020)

13. W. Qian, B. Milkereit, G. McDowell, K. Stevens, S. Halladay, Borehole Resistivity Logging and Tomography for Mineral Exploration. Proc. Explor. 07 Fifth Decenn. Int. Conf. Miner. Explor., 1115-1118 (2007)

14. Y. Li, D. W. Oldenburg, 3-D inversion of induced polarization data. 65, 1931-1945 (2000)

15. M. H. Loke, R. D. Barker, Least-squares deconvolution of apparent resistivity pseudosections. Geophysics. 60, 1682-1690 (1995)

16. M. H. Loke, R. D. Barker, Rapid least-squares inversion of apparent resistivity pseudosections by a quasi-Newton method. Geophys. Prospect. 44, 131-152 (1996)

17. V. N. Dakhnov, M. G. Latishova, V. A. Ryapolov, Investigation of wells by the induced polarization method (electrolytic well logging): Sb. Promisl. Geofiz. Vnetoneft, 46-82 (1952)

18. W. Qian, B. Milkereit, G. McDowell, K. Stevens, S. Halladay, Borehole resistivity logging and tomography for mineral exploration. Proc. Explor. 7, 1115-1118 (2007)

19. P. C. Lightfoot, B. Milkereit, others, in Proceedings of Exploration (2007), vol. 7, pp. 629-646

20. G. C. Begg, J. M. A. Hronsky, W. L. Griffin, S. Y. O’Reilly, in Processes and Ore Deposits of Ultramafic-Mafic Magmas through Space and Time (Elsevier, 2018), pp. 146

21. S. Yang, W. Qu, Y. Tian, J. Chen, G. Yang, A. Du, Origin of the inconsistent apparent Re-Os ages of the Jinchuan Ni-Cu sulfide ore deposit, China: Post-segregation diffusion of Os. Chem. Geol. 247, 401-418 (2008)

22. P. C. Lightfoot, C. E. G. Farrow, Geology, geochemistry, and mineralogy of the Worthington offset dike: A genetic model for offset dike mineralization in the Sudbury Igneous Complex. Econ. Geol. 97, 1419-1446 (2002)

23. A. J. Naldrett, Magmatic sulfide deposits: Geology, geochemistry and exploration (Springer Science \&amp; Business Media, 2013)

24. D. H. Rousell, J. S. Fedorowich, B. O. Dressler, Sudbury Breccia (Canada): a product of the $1850 \mathrm{Ma}$ Sudbury Event and host to footwall Cu--Ni--PGE deposits. Earth-Science Rev. 60, 147-174 (2003)

25. J. E. Hawley, The Sudbury ores, their mineralogy and origin; Part 1, The geological setting. Can. Mineral. 7, 1-29 (1962)

26. R. B. Hearst, W. A. Morris, Regional gravity setting of the Sudbury Structure. Geophysics. 66, 1680-1690 (2001)

27. R. A. F. Grieve, D. Stoeffler, A. Deutsch, The Sudbury structure: Controversial or misunderstood? J. Geophys. Res. Planets. 96, 22753-22764 (1991)

28. D. E. Ames, A. Davidson, N. Wodicka, Geology of the giant Sudbury polymetallic mining camp, Ontario, Canada. Econ. Geol. 103, 1057-1077 (2008)

29. D. Stöffler, M. Avermann, L. Bischoff, P. Brockmeyer, A. Deutsch, B. O. Dressler, R. 
Lakomy, V. Müller-Mohr, Sudbury, Canada: remnant of the only multi-ring (?) impact basin on Earth. Meteoritics. 24, 328 (1989)

30. A. Deutsch, R. A. F. Grieve, M. Avermann, L. Bischoff, P. Brockmeyer, D. Buhl, R. Lakomy, V. Müller-Mohr, M. Ostermann, D. Stöffler, The Sudbury structure (Ontario, Canada): A tectonically deformed multi-ring impact basin. Geol. Rundschau. 84, 697709 (1995)

31. T. E. Krogh, D. W. Davis, F. Corfu, E. G. Pye, in The geology and ore deposits of the Sudbury structure (Ontario Geological Survey Toronto, Ont., Canada, 1984), 1, 431446, (1984)

32. P. C. Lightfoot, I. A. Zotov, others, Geology and geochemistry of the Sudbury Igneous Complex, Ontario, Canada: Origin of nickel sulfide mineralization associated with an impact-generated melt sheet. Geol. Ore Depos. C/C Geol. Rudn. Mestorozhdenii. 47, 349 (2005)

33. A. J. Naldrett, R. H. Hewins, E. G. Pye, P. E. Giblin, others, The main mass of the Sudbury Igneous Complex. Geol. Ore Depos. Sudbury Basin. Spec. 1, 235-252 (1984)

34. P. C. Lightfoot, R. R. Keays, G. G. Morrison, A. Bite, K. P. Farrell, Geologic and geochemical relationships between the contact sublayer, inclusions, and the main mass of the Sudbury Igneous Complex; a case study of the Whistle Mine Embayment. Econ. Geol. 92, 647-673 (1997)

35. R. R. Keays, P. C. Lightfoot, Formation of Ni--Cu--platinum group element sulfide mineralization in the Sudbury impact melt sheet. Mineral. Petrol. 82, 217-258 (2004)

36. P. C. Lightfoot, Nickel sulfide ores and impact melts: Origin of the Sudbury Igneous Complex (Elsevier, 2016)

37. W. A. Morris, Paleomagnetism of some sulphide occurrences from the south range of the Sudbury Basin: J. Can. Soc. Expl. Geophys. 17, 55-71 (1981)

38. G. G. Morrison, others, Morphological features of the Sudbury structure in relation to an impact origin. Geol. ore Depos. Sudbury Struct. Ed. by EG Pye, AJ Naldrett, PE Giblin. Ontario Geol. Surv. Spec. 1, 513-520 (1984)

39. G. G. Morrison, B. C. Jago, T. L. White, others, Footwall mineralization of the Sudbury Igneous Complex. Ontario Geol. Surv. 5, 119-132 (1994)

40. D. J. Marshall, T. R. Madden, Induced polarization, a study of its causes. Geophysics. 24, 790-816 (1959)

41. J. S. Sumner, Principles of induced polarization for geophysical exploration (Elsevier, 2012), 5

42. J. H. Schön, Physical properties of rocks: Fundamentals and principles of petrophysics (Elsevier, 2015), 65

43. S. H. Ward, B. K. Sternberg, D. J. LaBrecque, M. M. Poulton, Recommendations for IP research. Lead. Edge. 14, 243-247 (1995)

44. I. M. Johnson, Spectral induced polarization parameters as determined through timedomain measurements. Geophysics. 49, 1993-2003 (1984)

45. D. Santoso, A. Laesanpura, B. Sulistijo, S. Bahri, I. Suyanto, others, Application of Time Domain Induced Polarization (TDIP) Methods to Metallic Minerals Prospect on Kasihan Region, Pacitan Regency, East Java, Indonesia. Int. J. Econ. Environ. Geol., 16-23 (2019)

46. H. O. Seigel, Mathematical formulation and type curves for induced polarization. Geophysics. 24, 547-565 (1959)

47. W. M. Telford, W. M. Telford, L. P. Geldart, R. E. Sheriff, R. E. Sheriff, Applied geophysics (Cambridge university press, 1990), 1

48. J. Palich, W. Qian, C. Creek, I. Consulting, EarthPrabMeeting the Challenges of Gold Exploration through High Resolution Borehole and Surface IP. Geophys. Explor. Geophys. Expand. Abstr. (2010) 
49. J. J. Daniels, A. V Dyck, Borehole resistivity and electromagnetic methods applied to mineral exploration. IEEE Trans. Geosci. Remote Sens., 80-87 (1984)

50. B. Zhou, S. A. Greenhalgh, Cross-hole resistivity tomography using different electrode configurations. Geophys. Prospect. 48, 887-912 (2000) 